\title{
Importance of the use of protocols for the management of analgesia and sedation in pediatric intensive care unit
}

\author{
Emiliana Motta ${ }^{1 *}$, Michele Luglio ${ }^{2}$, Artur Figueiredo Delgado ${ }^{3}$, Werther Brunow de Carvalho ${ }^{4}$ \\ ${ }^{1}$ Assistant Physician at the Pediatric Intensive Care Unit (PICU), Instituto da Criança, Hospital das Clínicas, Faculdade de Medicina, Universidade de São Paulo (HC-FMUSP), São Paulo, SP, Brazil \\ ${ }^{2}$ Clinical Preceptor at the PICU, Instituto da Criança, HC-FMUSP, São Paulo, SP, Brazil \\ ${ }^{3}$ Professor, Habilitation (BR: Livre-docência), Department of Pediatrics, FMUSP. Coordinator of the PICU, Instituto da Criança, HC-FMUSP, São Paulo, SP, Brazil \\ ${ }^{4}$ Full Professor of Intensive Care/Neonatology, Department of Pediatrics, FMUSP, São Paulo, SP, Brazil
}

Study conducted at Instituto da Criança, Hospital das Clínicas, Faculdade de Medicina, Universidade de São Paulo (HC-FMUSP), São Paulo, SP, Brazil

Article received: 6/29/2016 Accepted for publication: $7 / 26 / 2016$

*Correspondence: Centro de Terapia Intensiva Pediátrica Address: Av. Dr. Enéas de Carvalho Aguiar, $647,4^{\circ}$ andar São Paulo, SP - Brazil Postal code: 05403-000 emiliana.motta@hc.fm.usp.br

\section{SUMMARY}

Introduction: Analgesia and sedation are essential elements in patient care in the intensive care unit (ICU), in order to promote the control of pain, anxiety and agitation, prevent the loss of devices, accidental extubation, and improve the synchrony of the patient with mechanical ventilation. However, excess of these medications leads to rise in morbidity and mortality. The ideal management will depend on the adoption of clinical and pharmacological measures, guided by scales and protocols.

Objective: Literature review on the main aspects of analgesia and sedation, abstinence syndrome, and delirium in the pediatric intensive care unit, in order to show the importance of the use of protocols on the management of critically ill patients. Method: Articles published in the past 16 years on PubMed, Lilacs, and the Cochrane Library, with the terms analgesia, sedation, abstinence syndrome, mild sedation, daily interruption, and intensive care unit.

Results: Seventy-six articles considered relevant were selected to describe the importance of using a protocol of sedation and analgesia. They recommended mild sedation and the use of assessment scales, daily interruptions, and spontaneous breathing test. These measures shorten the time of mechanical ventilation, as well as length of hospital stay, and help to control abstinence and delirium, without increasing the risk of morbidity and morbidity.

Conclusion: Despite the lack of controlled and randomized clinical trials in the pediatric setting, the use of protocols, optimizing mild sedation, leads to decreased morbidity.

Keywords: pediatrics, intensive care unit, analgesia, sedation, daily interruption, abstinence syndrome, delirium.

\section{INTRODUCTION}

Intensive care hospitalization exposes the patient to pain and a series of stressful events that can cause it. Analgesia and sedation are key elements fundamental to the care of these critically ill patients, especially those on mechanical ventilation. The main indications to these medications are: to better manage pain, anxiety, and agitation; promote amnesia; facilitate synchrony with the mechanical ventilation; avoid loss of catheters and endotracheal tube; and reduce cellular metabolism. ${ }^{1-4}$ However, in spite of helping to manage these conditions, it is still difficult to reach adequate level of sedation and an- algesia, avoiding excesses and subdose. An ideal level of sedation is described as an estate on which the patient is sleepy, responding to environmental stimuli, without risks and excessive movements. In this condition, the child is conscious, with spontaneous breathing and comfortable in the mechanical ventilation, tolerating other intervention. However, practice has shown that excessive sedation, often driven by fear of loss of devices and accidental tracheal extubation, results in increased duration of mechanical ventilation in days, longer length of stay in the intensive care unit (ICU) and overall hospital stay, cerebral dysfunction, drug tolerance, absti- 
nence syndrome and delirium, thus increasing the cost of hospitalization. For better management of these patients, the use of scales and protocols of analgesia and sedation, associated with mild sedation and daily interruption, is associated with lower use and shorter duration of sedation, mechanical ventilation, and length of hospital and ICU stay (as described by the Society of Critical Care Medicine - SCCM). ${ }^{1-4}$

\section{Objective}

The objective is to review the main aspects of sedation and analgesia in pediatric intensive care units, including the use of scales for patient management, daily interruption, adequate level of sedation, abstinence syndrome, and delirium. In the end, to promote the use of protocols, with the main aspects to lower the use of sedatives through the use of sedation and analgesia scales, improving multidisciplinary communication and lowering hospital and length of ICU stay.

\section{Method}

We conducted a review of the medical literature of the last 16 years (2000-2016) utilizing PubMed, Lilacs, and the Cochrane Library with the following terms: sedation, analgesia, mild sedation, daily interruption, child, intensive care medicine. The most relevant articles on sedation and analgesia in ICU, use of sedation/analgesia scales, daily interruption, abstinence, and delirium published in English and Portuguese were included. The papers selected for this review included one meta-analysis, six systematic reviews, 20 narrative reviews, six guidelines, nine prospective randomized studies, three cohort studies, three case series, one case-control study, three clinical trials, eight scale validation studies, six prospective observation studies, eight cross-sectional studies, two letters to the editor.

\section{Results}

Management of the patient in the pediatric intensive care unit While the use of adequate sedation and analgesia reduce the response to stress and improve clinical and psychological outcomes, a subdose of these drugs would lead to pain, discomfort, possible accidental extubation, and loss of devices. Overdose, in the other hand, would lead to a need for longer duration of mechanical ventilation, increased hospital and ICU length of stay, tolerance, abstinence, and delirium. To reach an ideal level of sedation, we should use other measures for better patient comfort. Such measures, known as non-pharmacological, are essential, helping on the management of patients and on the reduction of agitation, of unfavorable cognitive outcomes - such as dis- ruptions of the sleep-wake cycle and delirium. Non-pharmacological strategies should be carried out and checked every time since the admission to the unit. .,2,-7 $^{1}$

Among the non-pharmacological measures are minimization of noise in the unit - which must be as silent as possible; utilization of adequate luminosity to promote an adequate sleep-awake cycle - through less light during nighttime; promoting time to rest and sleep to maintain a circadian orientation; concentrating, as much as possible, the procedures on daytime; keeping the patient in a comfortable position, with the use of cushions, for example; stimulating the presence of companions; maintaining good communication between everyone and the medical team. The use of video-therapy and music-therapy are also procedures to promote comfort to these patients. ${ }^{1,2,47}$

\section{Management of pain/sedation}

The International Association for the Study of Pain defines pain as a sensorial and emotional, unpleasant experience, associated with an actual or potential lesion to tissues. In the ICU, we can distinguish between two types of pain: (1) acute pain, including procedure and post-operative pain; and (2) prolonged pain - which is pain caused by a disease (like peritonitis, mechanical ventilation, tubes and drains etc.), with predictable beginnings and endings. ${ }^{4,8,9}$

In spite of being a subjective parameter, all teams must be prepared to recognize and treat pain, because response to pain stress promotes an increase in endogenous catecholamine, leading to arteriolar vasoconstriction, worsening of tissue perfusion and reduction of tissue $\mathrm{pO}_{2}$; hypercatabolic state, lipolysis, hyperglycemia; and increased infection risk. So, identifying and treating pain adequately requires attention and precise therapeutic interventions. ${ }^{9,10}$

Recent studies demonstrate that the use of scales to improve recognition of pain and its pharmacological and non-pharmacological management is crucial. A self-report made by the patient is considered the gold-standard method to measure an intervention on pain. This can be done through numerical (a graduation of pain from 0 without pain - to 10, unbearable pain) and visual scales (numbers or faces). However, such methods are not always useful in children, because of age, neurological dysfunction or lack of adequate communication due to the presence of endotracheal tube and mechanical ventilation. ${ }^{4,9,10}$ Scales were developed and validated due to theses difficulties, and their use is now well established for the evaluation and intervention on pediatric pain. ${ }^{9-18}$

The implementation of scales has already shown to be plausible and effective on intensive care units, both adult 
and pediatric. Mansouri $\mathrm{P}$ et al. demonstrated a decrease of 3 days in ICU stay with the use of protocols and scales for analgesia and sedation. ${ }^{20}$ According to Larson EG et al., the use of scales improves communication within the multidisciplinary team, and thus the therapeutic plan and patient management. ${ }^{22}$ Only one recent study, by Curley MAW et al., showed that the use of protocol did not alter the duration of mechanical ventilation, but with a complex relation between pain, agitation, and alertness, and a lower use of medication, with no more adverse events. ${ }^{24}$

As already described by Harris J et al., the FLACC scale and the Multidimensional Assessment of Pain Scale (MAPS) are indicated to evaluate pain in critically ill children. There is no clear literature recommendation on the frequency on which these scales should be applied, which depends on the therapeutic goals and the clinical state of the patient. ${ }^{4,10-16,23}$

Merkel SI et al. created the FLACC scale in 1997, for children aged from 2 months to 7 years in a post-surgical setting. ${ }^{19}$ The name FLACC is an acronym of five categories: Face, Legs, Activity, Cry, Consolability. Each category scores 0 to 2 points, totaling 10 points. The resulting score correlates with the degree of pain: 0 for no pain or comfortable; 1-3 for mild pain; 4-6 for moderate pain; and 7-10 for intense pain. ${ }^{11,19}$ The use of the FLACC scale was posteriorly extended and various studies showed that its use is reproducible and feasible in many age groups, clinical settings, and cognitive states. As evaluated by Malviya $S$ et al., the FLACC scale can be individualized for use in children with altered cognitive states. ${ }^{12}$ Nilsson $\mathrm{S}$ et al. showed that FLACC scale is adequate for children between 5 and 16 years of age. ${ }^{14}$ Voepel-Lewis $\mathrm{T}$ et al. validated the use of FLACC in intensive care units, with a good correlation with numeric $0-10$ scales. ${ }^{15}$ The scale was translated and validated for use in Portuguese language. ${ }^{13}$

After the non-pharmacological measures have been adopted and the most adequate scale has evaluated the patients, we shall initiate the pharmacological treatment of pain. The choice of drug depends on the degree of pain of the patient, given by the scale and its clinical condition. In cases of mild pain, is indicated the use of non-opioid analgesics, like acetaminophen and - with care in the pediatric setting - nonsteroidal anti-inflammatory drugs (NSAIDs), such as ketorolac. In moderate pain, association of a weak opioid, such as tramadol, is recommended. In intense pain, the use of strong opioids is indicated, such as morphine, fentanyl, and methadone. Adjuvant medications, including gabapentin and carbamazepine, can also be used., ${ }^{9,10,25}$

In intensive care units, intravenous opioids are considered the first line of drugs for the treatment of pain.
Recently, studies showed that the use of opioids constitute the primary regimen for analgesia/sedation in ICU. ${ }^{9,10,21}$ Fentanyl is the most used opioid, being used by $66 \%$ of the intensive care physicians, as shown by Kudchadkar SR et al., ${ }^{26}$ due to a lower incidence of side effects when compared to morphine. . $^{21,26}$

\section{Management of sedation/agitation}

Patients admitted to intensive care units present some degree of discomfort, physical or psychic distress, sometimes requiring the use of sedatives, especially those in mechanical ventilation. Reaching optimal/mild sedation is ideal, avoiding oversedation or subdoses, each with its own adverse reactions. ${ }^{1,2,4}$ As described by Hughs $C G$ et al., profound sedation along the first 24 hours is associated to an increase of 12 hours ( $\mathrm{p}=0.0001$ ) of mechanical ventilation; increase in $10 \%$ of in-hospital mortality ( $\mathrm{p}=0.01$ ) and $8 \%$ in 180 days mortality ( $\mathrm{p}=0.03)$. The use of protocols of sedation, mild sedation, daily interruption with spontaneous breathing test is recommended in order to decrease ventilatory needs, hospitalization time and cognitive impairment. ${ }^{2-4,9,10,27-33}$ The implementation of the mnemonic $\mathrm{ABCDE}$ bundle program (Awakening and Breathing coordination, attention to the Choice of sedation, Delirium monitoring, and Early mobility and Exercise) in adults showed success in providing less days of mechanical ventilation $(\mathrm{p}=0.04)$ and in lowering delirium incidence $(\mathrm{p}=0.004){ }^{30}$

The use of sedation scales is useful and recommended to reach mild sedation, which is considered ideal. The patient must be calm, responsive to stimuli, comfortable in the mechanical ventilation. ${ }^{4,9,10}$ Hughes et al. demonstrated that the use of mild sedation promotes a decrease in ventilatory support time in nearly 2.6 days $(\mathrm{p}=0.02)$, reduction of ICU stay in 3 days ( $\mathrm{p}=0.03$ ), without increase in accidental tracheal extubation and needs of re-intubation. ${ }^{3}$

The use of sedation scales is yet difficult to implement in ICUs, with a study by Hudchadkar et al. showing that scales are routinely used in only $42 \%$ of the American pediatric ICUs. ${ }^{21}$ Nevertheless, its use is recommended as an attempt to reduce the duration of mechanical ventilation, length of ICU and hospital stay.,22,23,27 In pediatrics, in 1992, Ambuel et al. developed a method to evaluate sedation in ventilated patients, the COMFORT scale, which aggregates six behavioral and two physiological parameters. However, the two physiological parameters (blood pressure and heart rate) were excluded to avoid confounding the evaluation and a new scale was validated, the COMFORT Behavior scale, ${ }^{30-32}$ which is the scale recommended (level A evidence) for management and evaluation of sedation in pediatrics, used every 4 to 8 hours, as 
required based on the patient conditions. ${ }^{4,33}$ The COMFORT-B scale is also validated in Portuguese, with its use recommended. ${ }^{34}$

The daily interruption is being used for a long time in adult ICUs, demonstrating benefits such as a 2.4-day decrease in mechanical ventilation $(\mathrm{p}=0.004)$ and a 3.5 -day decrease in length of ICU stay $(\mathrm{p}=0.02)$, without increase in the number of complications. ${ }^{3}$ Daily interruption of sedation has always been discussed in pediatric ICU because of technical difficulties when compared to adult practice, greater risk of adverse events, including accidental tracheal extubation, and loss of invasive devices. Nevertheless, recent studies showed success in the use of daily interruption in pediatric ICUs. Gupta et al. demonstrated a decrease in duration of ventilatory support, leading to a reduction from 13.01 days in the control group to 8.4 days in the daily interruption group ( $\mathrm{p}=0.028)$; shorter length of ICU stay, from 14 days in the control group to 11 days in the intervention group ( $\mathrm{p}=0.023)$; lower doses of midazolam used in the daily interruption group $(\mathrm{p}=0.002)$, implicating lower hospitalization costs without an increase in the number of adverse events. ${ }^{35}$ Another study, by Verlaat et al., showed similar results, with a significant decrease in sedative and analgesic agents used; less time of mechanical ventilation and decreased length of ICU stay with no increase in the numbers of adverse events. ${ }^{36} \mathrm{~A}$ recent study by Vet $\mathrm{NJ}$ et al., however, did not show much benefit in the use of daily interruption strategies to shorten the duration of mechanical ventilation or hospitalization, or the quantities of sedatives used, with the use of these strategies potentially associated with a higher 30-day mortality rate, without explaining the reasons behind this fact. ${ }^{37,38}$

The use of daily interruption together with spontaneous breathing tests also showed benefits in the reduction of the need for ventilatory support in 3 days $(\mathrm{p}=0.002)$, ICU length of stay in 3.8 days $(\mathrm{p}=0.01)$ and length of hospital stay in 4.3 days $(\mathrm{p}=0.04) .^{3}$

The choice of the ideal sedative agent is difficult, and must take into account the pharmacology of the drugs and the different pathologies. New studies have shown that the use of benzodiazepines leads to a longer need for ventilatory support ( 1.9 days, $\mathrm{p}<0.00001$ ) and longer ICU length of stay ( 1.65 days, $\mathrm{p}=0.0005$ ), as demonstrated by a review and meta-analysis by Fraser et al. ${ }^{29,39}$ Also, it was shown that the prevalence of delirium, in the use of nonbenzodiazepine agents, is lower, implicating in smaller hospitalization cost..$^{29,40}$ Recently, the preferential use of non-benzodiazepine sedatives, such as dexmedetomidine and propofol, has been advocated based on the Pain, Agitation and Delirium (PAD) guidelines for adult patients. ${ }^{9}$
Propofol is a safe drug for adult use; however, it is not yet approved for continuous infusion in children due to the higher risks of propofol infusion syndrome, which can be lethal, more common in those patients with concomitant use of cathecolamines and corticosteroids. ${ }^{41-43}$ Recent studies by Koriyama et al. and by Krussell et al. showed that the use of continuous infusion of propofol limited to $4 \mathrm{mg} / \mathrm{kg} / \mathrm{h}$ for less than 48 hours is safe, with no cases of propofol infusion syndrome reported in children. ${ }^{44,45}$

Another sedative agent indicated for adult use, with benefits over benzodiazepines, is dexmedetomidine, an alfa2 agonist with sedative and analgesic properties. Riker et al. demonstrated a decrease in duration of mechanical ventilation and a reduction in the prevalence of delirium in adults, when comparing the use of dexmedetomidine to benzodiazepines ${ }^{46}$ MacLaren et al. showed a lower incidence of delirium without more adverse reactions. ${ }^{47}$ Ozaki et al. studied the use of continuous infusion of dexmedetomidine in pediatric setting, for longer than the recommended time of 48 hours and at doses of $0.7 \mathrm{mcg} / \mathrm{kg} / \mathrm{h}$. The patients reached a good level of sedation with the use of the drug for nearly 6 days, with no more adverse events, rebound symptoms or abstinence. ${ }^{48}$ Other studies showed that the use of dexmedetomidine is safe in patients with congenital heart diseases and in the post-operatory of cardiac surgery without hypotension and bradycardia harmful to the patient. ${ }^{49-53}$

\section{Management of abstinence syndrome}

Prolonged administration of opioids and/or benzodiazepines leads to tolerance. Rapid suspension of these medications implicates a myriad of signs and symptoms, called abstinence syndrome. However, its diagnosis is complicated in virtue of a superposition of signs of pain, agitation, discomfort, and delirium. These factors must be excluded to confirm the diagnosis of abstinence, especially in children that received more than 5 days of sedation/ analgesia. Abstinence syndrome has a prevalence of 34 $70 \%$ in patients in use of analgesia/sedation, leading to problematic consequences, including increased morbidity, length of stay, and psychological alterations. ${ }^{54,55}$ To improve its evaluation, the use of assessment scales, such as the WAT-1 scale (Assessment Tool Version-1) or the SOS scale (Sophia Observation withdrawal Symptoms) ${ }^{4}$ (A-level recommendation by Harris et al. guideline ${ }^{4}$ ), is recommended. The WAT- 1 scale is already validated in pediatrics and translated into Portuguese. ${ }^{56}$

There is no consensus regarding the management scheme of opioid or benzodiazepine weaning in the abstinence syndrome, but many studies have been performed on the recognition of this entity, its monitoring 
and treatment. ${ }^{57-59}$ Tobias et al., in 2000, proposed a treatment based on the conversion of midazolam to lorazepam and fentanyl to methadone, through the relation between potency and half-life, with slow weaning based on weakly reductions of $20 \%$ of its dose. ${ }^{60}$ Bowens et al. compared the weaning of opioids with low and high doses of methadone, showing no difference between the two approaches. ${ }^{61}$ Other studies demonstrated the implementation of a protocol for the management of abstinence syndrome reduces the time and dosage of those drugs, while the WAT-1 scale has a good performance evaluating abstinence. ${ }^{62-66}$ Fernandez-Carrión et al. showed that reductions of $10 \%$ in the doses of methadone every day implied in no increase in the incidence of signs and symptoms of abstinence, needs of morphine rescue therapy, or excess sedation. ${ }^{58}$ Some other studies show that daily reductions of $5-10 \%$ in the doses used between 5 and 10 days did not demonstrate adverse effects, suggesting that a faster approach on weaning leaded to a decrease in length of stay, without any increase in morbidity. ${ }^{55,57}$ Oschman et al. show that the use of other drugs is possible in the treatment of abstinence, such as dexmedetomidine and clonidine. ${ }^{67}$

\section{Delirium}

Delirium represents an acute cerebral dysfunction, characterized by an altered mental state and behavior. According to the Diagnostic and Statistical Manual of Mental Disorders (DSM-5) definition, diagnostic criteria for delirium include: disruption of attention and consciousness, accompanied by cognitive impairment (memory, orientation, language, and perception) that cannot be explained by other previous neurocognitive disturbances; this develops in hours or days, frequently with fluctuations throughout the day and worsening during nighttime, and there is evidence that these effects result from clinical conditions or treatment (infection, cancer, metabolic or endocrine alterations, use of sedatives). Delirium can be either hypoactive (apathy, slowed speech, lethargy; a condition with poorer prognosis), hyperactive (agitation, emotional fluctuation, hallucinations) or mixed. It is associated with worse outcomes, longer length of stay, more cognitive impairment and higher mortality rates in adults up until three times higher than the general population, along 6 months of observation. ${ }^{4,68-70}$

The prevalence in adults is well established, varying from 45 to $87 \%$ of the patients in ICUs. ${ }^{69,70}$ In pediatrics, there are still few studies, with some of then showing a prevalence of $4-29 \% .{ }^{4,70}$
Risk factors for delirium, in adults, include the well-documented use of midazolam, which became less and less used in this population of patients, leading to the use of dexmedetomidine and propofol as sedative agents. Besides this, immobilization, long length of stay, alterations on sleep-awake cycle, lack of present companions, infection, presence of invasive devices are also described as risk factors for the development of delirium. ${ }^{69}$ In the pediatric population, Silver et al., in a prospective study, described some risk factors, such as: previous alterations on mental status $(p<0.0001)$, necessities of oxygen therapy $(p<0.0001)$, use of mechanical ventilation ( $\mathrm{p}<0.0001$ ), profound sedation $(\mathrm{p}<0.0001)$, pre-scholar age group $(\mathrm{p}=0.007){ }^{71}$

The early recognition of delirium is shown to be essential, in virtue of the high mortality and morbidity associated with it. So, the use of evaluation scales every 8 to 12 hours is recommended. ${ }^{4,68-70}$ In pediatrics, there is still no consensus regarding the best method. Options include the p-CAM (pediatric Confusion Assessment Method), derived from the CAM scale, for children older than 5 years of age, and the CAP-D (Cornell Assessment Pediatric Delirium tool) for children between 0-18 years old. ${ }^{4,68,70,72}$

\section{Discussion}

Promotion of comfort and lowering of anxiety, fear, and anguish is part of the daily routine of a pediatric intensive care physician. The use of an excessive dosage of sedatives and analgesics leads to worse outcomes, with longer periods of immobilization, more sleep-awake cycle disturbances and delirium, increase in time of mechanical ventilation and hospital length of stay, higher treatment costs.

The use of analgesia and sedation scales is well documented, favoring a better communication within the multidisciplinary team, better choice of medication when taking into account the pharmacokinetic and pharmacodynamics of the drugs, their interaction with different age groups and pathologies. In addition, avoiding excessive sedation and analgesia promotes ideal mild sedation, causing the patient to remain calm, responsive to stimuli, and comfortable under mechanical ventilation.

In the initial management, analgesia with the use of strong opioids, like fentanyl, and with mild sedation, is preconized. After adequate analgesia, the use of sedative agents should be taken into account, avoiding, if possible, the use of benzodiazepines, as it was shown to lead to negative outcomes in delirium and increased morbidity/mortality. The use of other therapeutic agents, such as dexmedetomidine, clonidine, propofol (if possible), and ketamine, is indicated. 
The use of daily interruption of sedation and spontaneous breathing test are also more established in the pediatric population, with a decrease in the duration of ventilatory support and length of ICU stay, without an increase in the numbers of accidental tracheal extubation and loss of invasive devices.

The diagnosis of delirium is still difficult in the pediatric setting and there are few randomized studies on this topic. Its recognition is increasingly taken into account and pediatric intensive care physicians must be alert to prevent it. The use of scales is recommended, such as the recent $\mathrm{p}-\mathrm{CAM}, \mathrm{CAP}-\mathrm{D}$ and sp-CAM. The use of preventive measures, including early passive or active mobilization, promotion of a good sleep-awake cycle, light and noise control, and the constant presence of family members, must be adopted in the pediatric ICU.

More and more pediatric ICUs should adopt such measures and interventions in order to provide better management of analgesia and sedation for the patients, controlling morbidity and mortality, with the use of protocols.

This protocol must include the management of analgesia and sedation, as well as the use of assessment scales such as FLACC, numeric and visual scales for pain and COMFORT-Behavior for sedation, by the nursing staff every 4 hours, instituting mild sedation, first with analgesic control, the with the use of sedatives, based on the scales' assessment; promote the use of daily interruption with spontaneous breathing test every day in patients in conditions for it; monitoring and treating abstinence syndrome with WAT-1 and the use of methadone and lorazepam, with fast weaning, in 5 to 10 days and daily reductions of its doses; assess and treat delirium, adopting non-pharmacological measures, such as early mobilization, promotion of the sleep-awake cycle, video and musical therapy, presence of family members, and the use of delirium assessment tools.

\section{Conclusion}

Offering perfect analgesia and sedation in pediatrics is still a controversy. There is a concern regarding the consequent over-sedation caused by high doses of sedatives and analgesics, which slow metabolism and clearance, impacting duration of mechanical ventilation and hemodynamic stability. However, the institution of therapy guided by protocols and assessment scales is necessary to prevent excessive or suboptimal use of sedatives, which leads to an increase in the duration of mechanical ventilation support, accidental tracheal extubation, abstinence and delirium. To reach this objective, a multidisciplinary approach is essential.

\section{Resumo}

Importância do uso de protocolos para manejo da analgesia e sedação em unidade de terapia intensiva pediátrica

Introdução: analgesia e sedação são elementos necessários no cuidado do paciente em UTI, com o objetivo de promover controle de dor, angústia, agitação e evitar perda de dispositivos, extubação acidental e melhora da sincronia do paciente com a ventilação mecânica. No entanto, o excesso dessas medicações ocasiona um aumento de morbidades e mortalidade. O manejo ideal depende da adoção de medidas clínicas e farmacológicas, guiadas por escalas e protocolos.

Objetivo: revisão da literatura sobre principais aspectos da analgesia e sedação, síndrome de abstinência e delirium em unidade de terapia intensiva pediátrica, mostrando a importância do uso de protocolos no manejo dos pacientes criticamente enfermos.

Método: artigos publicados nos últimos 16 anos, nas plataformas PubMed, Lilacs e Cochrane Library, com os termos analgesia, sedação, síndrome de abstinência, nível leve de sedação, interrupção diária da sedação e unidade de terapia intensiva.

Resultados: foram selecionados 76 artigos relevantes para descrever a importância da utilização do protocolo de sedação e analgesia, preconizando um nível leve de sedação, com uso de escalas de avaliação, interrupção diária e aplicação de teste de respiração espontânea. Essas medidas evidenciam uma diminuição no tempo de ventilação mecânica, no tempo de internação hospitalar, o controle da síndrome de abstinência e delirium, sem implicar em maior risco de morbimortalidade.

Conclusão: apesar da falta de estudos controlados e randomizados em pediatria, o uso de protocolo, otimizando um nível leve de sedação, determina uma menor morbidade.

Palavras-chave: pediatria, unidade de terapia intensiva, analgesia, sedação, interrupção diária da sedação, síndrome de abstinência, delirium.

\section{References}

1. Keogh SJ, Long DA, Horn DV. Practice guidelines for sedation and analgesia management of critically ill children: a pilot study evaluating guideline impact and feasility in the PICU. BMJ Open. 2015; 5(3):e006428.

2. Vet NJ, Ista E, Wildt SN, van Dijk M, Tibboel D, Hoog M. Optimal sedation in pediatric intensive care patients: a systematic review. Intensive Care Med. 2013; 39(9):1524-34.

3. Hughes CG, Girard TD, Pandharipande PP. Daily sedation interruption versus targeted light sedation strategies in ICU patients. Crit Care Med. 2013; 41(9):S39-45. 
4. Harris J, Ramelet A, van Dijk M, Pokorna P, Wielenga J, Tume L, et al. Clinical recommendations for pain, sedation, withdrawal and delirium assessment in critically ill infants and children: an ESPNIC position statement for healthcare professionals. Intensive Care Med. 2016; 42(6):972-86.

5. Playfor S, Jenkins I, Boyles C, Choonara I, Davies G, Haywood T, et al.; United Kingdom Paediatric Intensive Care Society Sedation; Analgesia and Neuromuscular Blockade Working Group. Consensus guidelines on sedation and analgesia in critically ill children. Intensive Care Med. 2006; 32(8):1125-36.

6. Jastremski CA. ICU bedside environment. A nursing perspective. Crit Care Clin. 2000; 16(4):723-34, xi.

7. Dingeman RS, Mitchell EA, Meyer EC, Curley MAQ. Parental presence during complex invasive procedures and cardiopulmonary resuscitation: a systematic review of the literature. Pediatrics. 2007; 120(4):842-54.

8. Pillai Riddell RR, Stevens BJ, McKeever P, Gibbins S, Aztalos L, Katz J, et al. Chronic pain in hospitalized infants: health professionals' perspectives. J Pain. 2009; 10(12):1217-25.

9. Barr J, Fraser GL, Puntillo K, Ely EW, Gélines C, Dasta JF, et al. ; American College of Critical Care Medicine. Clinical practice guidelines for the management of pain, agitation, and delirium in adult patients in the intensive care unit. Crit Care Med. 2013; 41(1):263-306.

10. Celis-Rodríguez E, Birchenall C, de la Cal MÁ, Arellano C, Hernández A, Ceraso D, et al.; Federación Panamericana e Ibérica de Sociedades de Medicina Crítica y Terapia Intensiva. [Clinical practice guidelines for evidence-based management of sedoanalgesia in critically ill adult patients]. Med Intensiva. 2013; 37(8):519-74.

11. Merkel S, Voepel-Lewis T, Malviya S. Pain assessment in infants and young children: the FLACC scale. A behavioral tool to measure pain in young children. AJN. 2002; 102(10):55-8.

12. Malviya S, Voepel-Lewis T, Burke C, Merkel S, Tait AR. The revised FLACC observational pain tool: improved reliability and validity for pain assessment in children with cognitive impairment. Pediatr Anaesth. 2006; 16(3):258-65.

13. Silva FC, Thuler LCS. Cross-cultural adaptation and translation of two pain assessment tools in children and adolescents. J Pediatr (Rio J). 2008; 84(4):344-9.

14. Nilsson S, Finnström B, Kokinsky E. The FLACC behavioral scale for procedural pain assessment in children aged 5-16 years. Pediatr Anaesth. 2008; 18(8):767-74.

15. Voepel-Lewis T, Zanotti J, Dammeyer JA, Merkel S. Reliability and validity of the face, legs, activity, cry, consolability behavioral tool in assessing acute pain in critically ill patients. Am J Crit Care. 2010; 19(1):55-61.

16. Silva LDG, Lima LS, Tacla MTGM, Ferrari RAP. Escalas de avaliação de dor: processo de implantação em uma unidade de terapia intensiva pediátrica. Revista enferm UFPE on line. 2014; 8(4):857-63.

17. Ramelet A, Rees NW, Mcdonald S, Bulsara MK, Huijer Abu-Saad H. Clinical validation of the multidimensional assessment of pain scale. Paediatr Anaesth. 2007; 17(12):1156-65.

18. Ramelet A, Rees NW, Mcdonald S, Bulsara MK, Abu-Saad HH. Development and preliminary psychometric testing of the Multidimensional Assessment of Pain Scale: MAPS. Paediatr Anaesth. 2007; 17(4):333-40.

19. Hicks CL, von Baeyer CL, Spafford PA, van Korlaar I, Goodenough B. The faces pain scale-revised: toward a common metric in pediatric pain measurement. Pain. 2001; 93(2):173-83.

20. Mansouri P, Javadpour S, Zand F, Ghodsbin F, Sabetian G, Masjedi M, et al. Implementation of a protocol for integrated management of pain, agitation, and delirium can improve clinical outcomes in the intensive care unit: a randomized clinical trial. J Crit Care. 2013; 28(6):918-22.

21. Kudchadkar SR, Yaster M, Punjabi NM. Sedation, sleep promotion, and delirium screening practices in the care of mechanically ventilated children: a wake-up call for the pediatric critical care community. Crit Care Med. 2014; 42(7):1592-600.

22. Larson GE, Arnup SJ, Clifford M, Evans J. How does the introduction of a pain and sedation management guideline in the paediatric intensive care impact on clinical practice? A comparison of audits pre and post guideline introduction. Aust Crit Care. 2013;26(3):118-23.

23. Dorfman TL, Schellenberg ES, Rempel GR, Scott SD, Hartling L. An evaluation of instruments for scoring physiological and behavioral cues of pain, non-pain related distress, and adequacy of analgesia and sedation in pediatric mechanically ventilated patients: a systematic review. Int J Nurs Stud. 2014; 51(4):654-76.

24. Curley MAQ, Wypji D, Watson S, Grant MJC, Asaro LA, Cheifetz IR, et al. Protocolized sedation vs usual care in pediatric patients mechanically ventilated for acute respiratory failure: a randomized clinical trial. JAMA. 2015; 313(4):379-89.
25. Verguese ST, Hannallah RS. Acute pain management in children. J Pain Res. 2010; 3:105-23.

26. Inturrisi CE. Clinical pharmacology of opioids for pain. Clin J Pain. 2002; 18(4 Suppl):S3-13

27. Poh YN, Poh PF, Buang SNH, Lee JH. Sedation guidelines, protocols, and algorithms in PICUs: a systematic review. Pediatr Crit Care Med. 2014; 15(9):885-92

28. Ranzani OT, Simpson ES, Augusto TB, Cappi SB, Noritomi DT; AMIL Critical Care Group. Evaluation of a minimal sedation protocol using ICU sedative consumption as a monitoring tool: a quality improvement multicenter project. Crit Care. 2014; 18(5):580.

29. Page VJ, McAuley DF. Sedation/drugs used in intensive care sedation. Curr Opin Anaesthesiol. 2015; 28(2):139-44.

30. Carnevale FA, Razack S. An item analysis of the COMFORT scale in a pediatric intensive care unit. Pediatr Crit Care Med. 2002; 3(2):177-80.

31. Van Dijk M, Peters JWB, van Deventer P, Tibboel D. The COMFORT Behavior Scale: a tool for assessing pain and sedation in infants. Am J Nurs. 2005; 105(1):33-6.

32. Johansson M, Kokinsky E. The COMFORT behavioural scale and the modified FLACC scale in paediatric intensive care. Nurs Crit Care. 2009; 14(3):122-30.

33. Oldham M, Pisani M. Sedation in critically ill patients. Crit Care Clin. 2015; 31(3):563-87.

34. Amoretti CF, Rodrigues GO, Carvalho PRA, Trotta EA. Validação de escalas de sedação em crianças submetidas à ventilação mecânica internadas em uma unidade de terapia intensiva pediátrica terciária. Rev Bras Ter Intensiva. 2008; 20(4):325-30.

35. Gupta K, Gupta VK, Muralindharan J, Singhi S. Randomized controlled Trial of interrupted versus continuous sedative infusions in ventilated children. Pediatr Crit Care Med. 2012; 13(2):131-5.

36. Verlaat CWM, Heesen GP, Vet NJ, de Hoog M, van der Hoeven JG, Kox M, et al. Randomized controlled trial of daily interruption of sedatives in critically ill children. Paediatr Anaesth. 2014; 24(2):151-6.

37. Vet NJ, Wildt SN, Verlaat CWM, Knibbe CAJ, Mooji MG, van Woensel JBM, et al. A randomized controlled trial of daily sedation interruption in critically ill children. Intensive Care Med. 2016; 42(2):233-44.

38. Zimmerman JJ, Watson S, Ely W. Daily sedation interruption in children warrants further study. Intensive Care Med. 2016; 42(6):1101-2.

39. Fraser GL, Devlin JW, Worby CP, Alhazzani W, Barr J, Dasta JF, et al. Benzodiazepine versus nonbenzodiazepine-based sedation for mechanically ventilated, critically ill adults: a systematic review and meta-analysis of randomized trials. Crit Care Med. 2013; 41(9):S30-8.

40. Bioc JJ, Magee C, Cucchi J, Fraser GL, Dasta JF, Edwards RA, et al. Cost effectiveness of a benzodiazepine vs a nonbenzodiazepine-based sedation regimen for mechanically ventilated, critically ill adults. J Crit Care. 2014; 29(5):753-7.

41. Fudickar A, Bein B. Propofol infusion syndrome: update of clinical manifestation and pathophysiology. Minerva Anestesiol. 2009; 75(5):339-44.

42. Orsini J, Nadkarni A, Chen J, Cohen N. Propofol infusion syndrome: case report and literature review. Am J Health Syst Pharm. 2009; 66(10):908-15.

43. Mirrakhimov AE, Voore P, Halytskyy O, Khan M, Ali AM. Propofol infusion syndrome in adults: a clinical update. Crit Care Res Pract. 2015; 2015:260385.

44. Koriyama H, DuffJP, Guerra GG, Chan AW; Sedation Withdrawal and Analgesia Team. Is propofol a friend or a foe of the pediatric intensivist? Description of propofol use in a PICU. Pediatr Crit Care Med. 2014; 15(2):e66-71.

45. Kruessell MA, Udink ten Cate FE, Kraus AJ, Roth B, Trieschmann U. Use of propofol in pediatric intensive care units: a national survey in Germany. Pediatr Crit Care Med. 2012; 13(3):e150-4.

46. Riker RR, Shehabi Y, Bokesch PM, Ceraso D, Wisemandle W, Koura F, et al.; SEDCOM (Safety and Efficacy of Dexmedetomidine Compared With Midazolam) Study Group. Dexmedetomidine vs midazolam for sedation of critically ill patients: a randomized trial. JAMA. 2009; 301(5):489-99.

47. MacLaren R, Preslaski CR, Mueller SW, Kiser TH, Fish DN, Lavelle JC, et al. A randomized, double-blind pilot study of dexmedetomidine versus midazolam for intensive care unit sedation: patient recall for their experiences and shortterm psychological outcomes. J Intensive Care Med. 2015; 30(3):167-75.

48. Ozaki M, Takeda J, Tanaka K, Shiokawa Y, Nishi S, Matsuda K, et al. Safety and efficacy of dexmedetomidine for long-term sedation in critically ill patients. J Anesth. 2014; 28(1):38-50.

49. Whalen LD, Di Gennaro JL, Irby GA, Yanay O, Zimmermann JJ. Long-term dexmedetomidine use and safety profile among critically ill children and neonates. Pediatr Crit Care Med. 2014; 15(8):706-14. 
50. Burbano NH, Otero AV, Berry DE, Orr RA, Munoz RA. Discontinuation of prolonged infusions of dexmedetomidine in critically ill children with heart disease. Intensive Care Med. 2012; 38(2):300-7.

51. Lam F, Ransom C, Grossett JM, Kelkhoff A, Seib PM, Schmitz ML, et al. Safety and efficacy of dexmedetomidine in children with heart failure. Pediatr Cardiol. 2013; 34(4):835-41.

52. Chrysostomou C, Toledo JS, Avolio T, Motoa M, Berry D, Morell VO, et al. Dexmedetomidine use in a pediatric cardiac intensive care unit: Can we use it in infants after cardiac surgery? Pediatr Crit Care Med. 2009; 10(6):654-60.

53. Jiang L, Ding S, Yan H, Li Y, Zhang L, Chen X, et al. A retrospective comparison of dexmedetomidine versus midazolam for pediatric patients with congenital heart disease requiring postoperative sedation. Pediatr cardiol. 2015; 36(5):993-9.

54. Fernández-Carrión F, Gaboli M, González-Celador R, Gómez de QueroMasía PG, Fernández-de Miguel S, Murga-Herrera V, et al. [Withdrawal syndrome in the pediatric intensive care unit. Incidence and risk factors]. Med Intensiva. 2013; 37(2):67-74.

55. Birchley G. Opioid and benzodiazepine withdrawal syndromes in the paediatric intensive care unit: a review of recent literature. Nurs Crit Care. 2009; 14(1):26-37.

56. Franck LS, Harris SK, Soetenga DJ, Amling JK, Curley MA. The Withdrawal Assessment Tool-1 (WAT-1): an assessment instrument for monitoring opioid and benzodiazepine withdrawal symptons in pediatric patients. Pediatr Crit Care Med. 2008; 9(6):573-80.

57. Cho HH, O'Connell JP, Cooney M, Inchiosa MA Jr. Minimizing tolerance and withdrawal to prolonged pediatric sedation: case report and review of the literature. J Intensive Care Med. 2007; 22(3):173-9.

58. Lugo RA, MacLaren R, Cash J, Probble CG, Vernon DD. Enteral methadone to expedite fentanyl discontinuation and prevent opioid abstinence syndrome in the PICU. Pharmacotherapy. 2001; 21(12):1566-73.

59. Fisher D, Grap MJ, Younger JB, Ameringer S, Elswick RK. Opioid withdrawal signs and symptoms in children: frequency and determinants. Heart Lung. 2013; 42(6):407-13

60. Tobias J. Tolerance, withdrawal, and physical dependency after long-term sedation and analgesia of children in the pediatric intensive care unit. Crit Care Med. 2000; 28(6):2122-2132.
61. Bowens CD, Thompson JA, Thompson MT, Breitzka RL, Thompson DG, Sheeran PW. A trial of methadone tapering schedules in pediatric intensive care unit patients exposed to prolonged sedative infusions. Pediatr Crit Care Med. 2011; 12(5):504-11.

62. Steineck KJ, Skoglund AK, Carlson MK, Gupta S. Evaluation of a pharmacistmanaged methadone taper. Pediatr Crit Care Med. 2014; 15(3):206-10.

63. Tobias J. Methadone: who tapers, when, where, and how? Pediatr Crit Care Med. 2014; 15(3):268-70.

64. Anand KJS, Wilson DF, Berger J, Harrison R, Meert KL, Zimmerman J, et al.; Eunice Kennedy Shriver National Institute of Child Health and Human Development Collaborative Pediatric Critical Care Research Network. Tolerance and withdrawal from prolonged opioid use in critically ill children. Pediatrics. 2010; 125(5):e1208-25.

65. Franck LS, Scoppettuolo LA, Wypji D, Curley MA. Validity and generalizability of the Withdrawal Assessment Tool-1 (WAT-1) for monitoring iatrogenic withdrawal syndrome in pediatric patients. Pain 2012; 153(1):142-8

66. Ducharme C, Carnevale FA, Clermont M, Shea S. A prospective study of adverse reactions to the weaning of opioids and benzodiazepines among critically ill children. Intensive Crit Care Nurs. 2005; 21(3):179-86.

67. Oschman A, McCabe T, Kuhn RJ. Dexmedetomidine for opioid and benzodiazepine withdrawal in pediatric patients. Am J Health-Syst Pharm. 2011; 68(13):1233-8.

68. Silver G, Traube C, Kearney J, Kelly D, Yoon MJ, Nash Moyal W, et al Detecting pediatric delirium: development of a rapid observational assessment tool. Intensive Care Med. 2012; 38(6):1025-31.

69. Jackson P, Khan A. Delirium in critically ill patients. Crit Care Clin. 2015; 31(3):589-603.

70. Daoud A, Duff JP, Joffe AR. Diagnostic accuracy of delirium diagnosis in pediatric intensive care: a systematic review. Critical Care. 2014; 18(5):489.

71. Silver G, Traube C, Gerber LM, Sun X, Kearney J, Patel A, et al. Pediatric delirium and associated risk factors: a single-center prospective observational study. Pediatr Crit Care Med. 2015; 16(4): 303-9.

72. Brahmbhatt $\mathrm{K}$, Whitgob E. Diagnosis and management of delirium in critically ill infants: case report and review. Pediatrics. 2016; 137(3):e1-5. 